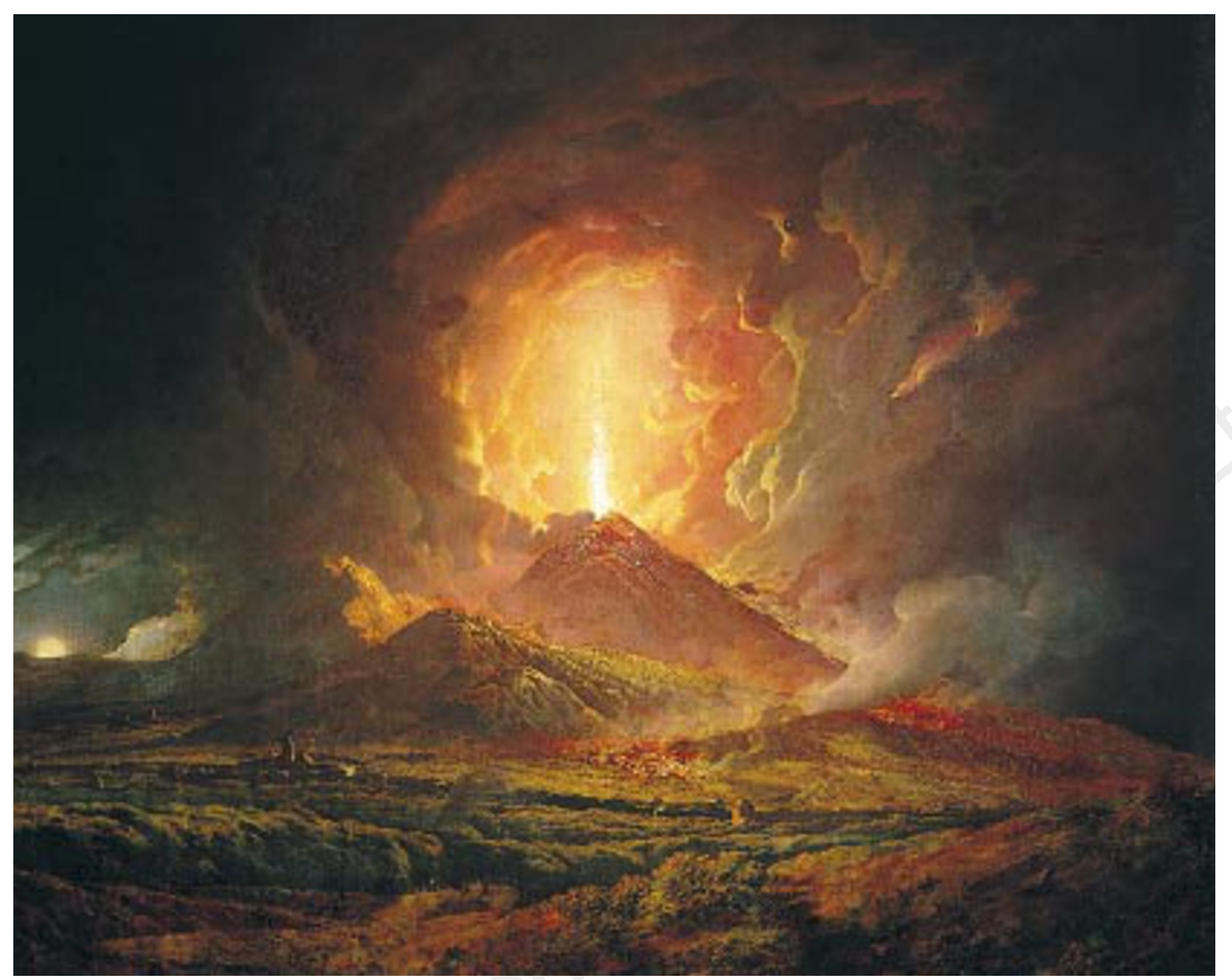

Wright's An Eruption of Vesuvius, Seen From Portici, c. 1774-76.

\title{
Wright's ruptions
}

\section{A volcanic eruption was a fitting subject for Joseph Wright. The artist had links with some of the great scientific thinkers in an age when science was beginning to discover the secrets of the forces that shape the Earth.}

\section{Martin Kemp}

oseph Wright of Derby's continued residence in his home town, far from condemning him to provincial isolation, located him within the remarkable orbit of the Lunar Society, whose luminaries included Josiah Wedgwood, James Watt, Matthew Boulton, Erasmus Darwin and Joseph Priestley.

Wright's exceptional range of subjectmatter extends beyond conventional landscapes and portraits into iron forges, industrial premises, alchemists' dens, air pumps and orreries, and plunges us visually into the rising scientific ferment of the second half of the eighteenth century. The sciences of chemistry, not least discoveries relating to combustion and oxygen, and of physics, particularly electricity, were revealing new dimensions to the forces that animate nature.

Volcanology played a significant role in demonstrating that the vast formative forces in the body of the Earth lay far beyond the scope of the biblical creation and Flood in time and magnitude. The discipline may be said to have been founded by Sir William Hamilton, King's Envoy in Naples, antiquar- ian and passionate observer of geological phenomena. In Hamilton's view, the now fertile fields of lava must be "so very ancient, as to be far out of the reach of history". Rugged topographies resulted not from God's static design but from huge effusions of material molten by subterranean fires "mountains are produced by volcanoes, not volcanoes by mountains" - a process that was still very much under way. Indeed, Hamilton believed that the present surface of the Earth contains no surviving part from its original, 'primitive' state.

Wright visited Vesuvius in 1774 , two years after Hamilton had published his Observations on Mount Vesuvius.... The painter wrote excitedly back to John Whitehirst in Derby that he had witnessed "a very considerable eruption... of which I am going to make a picture". Four years later Whitehirst was to publish his Inquiry into the Original State and Formation of the Earth, which talked about the great sea of inner fire that surged through what Wright called the "bowels of the mountain". In the event, Wright painted not one picture of Vesuvius, but more than 30 .

His series of pictures, composed in the stu- dio as sublime exercises in visual poetry, are seemingly different in method from Hamilton's professed system of "collecting facts".

The vertical jet of white-hot debris, the vortex of clouds and emergent Moon correspond less to what Wright witnessed at a single moment than to an artistic synthesis of the essence of Vesuvius's grandeur within the drama of world history.

The granular globs of white paint that comprise the jet and bedeck the fiery slopes stand for, rather than literally describe, the phenomenon.

Yet Wright's vision does strike to the very heart of the vitalistic and animistic enthusiasms that did so much to convince European scientists such as Luigi Galvani, Antoine Lavoisier, Alexander von Humboldt and Humphry Davy that the great key to the mystery of life lay in the kinds of universal electrochemical and combustive forces which twitched a frog's leg into life and breathed "Oxygenated Air" into every creature.

Martin Kemp is in the Department of the History of Art, University of Oxford, 35 Beaumont Street,

Oxford OX1 2PG, UK. 